\title{
Food waste to energy to food
}

\author{
S. R. Raftery \& R. C. Miner \\ Advanced Energy Growing ${ }^{\circledR}$, USA
}

\begin{abstract}
Food waste represents soil degradation, lost energy and water resources and a burden to our landfills and wastewater treatment systems. In the United States, approximately 50 percent of all food grown is wasted in large part, due to distance to markets, on average 1500-2000 miles/2414-3218 km, and the cultural norms of being a throwaway society. This food waste takes up 19 percent of our landfills, and contributes directly to our dependencies on fossil fuels (annually 19 percent of fossil fuels are used for agriculture) and depletion of nonrenewable fresh water sources. Add to this the 'flaring' of methane gases at most landfills, along with the $\mathrm{CO}^{2}$ emissions, food waste adds to the greenhouse gas issues. What is remarkable is how this waste remains invisible to most of the American population. The paper provides an overview to the food waste in the United States, and how there needs to have a paradigm shift to consider food waste as an energy source to grow food.

Keywords: food waste, food miles, consumer waste, landfills, anaerobic digesters, natural resource depletion, fresh water resources and food production.
\end{abstract}

\section{Introduction}

No one really knows how much food becomes waste in the global food system. From production, to processing, to retail sales, to preparation, cooking and serving, each step in the food system has significant levels of waste. It has been estimated that "half the world's food is lost, wasted, or discarded along the chain from the farm to shop to consumer to dump" [1]. While there are those who are working diligently to divert food waste from landfills, such as the European Union (EU) standard to reduce landfill tonnage, greenhouse gas emissions, and renewable energy creation [2], other developed nations such as the United States continue to give only limited attention to the issue of food waste. 
To understand why the average American citizen does not "think" about food, water, and waste, it may be necessary to understand the culture of abundance that has been part of the national psyche since the first settlements. From its earliest days, the United States possessed more arable land, natural resources, and geographic space than the early settlers from Europe had ever known. Successive generations of immigrants came with the same belief that America had an abundance of resources that could help them achieve the American dream. Only those Americans who lived through the era of the Great Depression and World War II ever experienced rationing, shortages, and scarcity in relation to food, fuel, and commercial goods in their daily lives. As this generation is rapidly disappearing, and the successive generations who, for over fifty years have known only prosperity, growth, and abundance, (while also being decoupled from the land where food is produced), is it any wonder that food, fuel, land, and water have become the invisible commodities to the average American.

It is human nature to value that, which costs more money. Perhaps this is where the average American citizen is disconnected from the food system. Few Americans realize that the United States has the cheapest food supply in the world - event taking into account the run-up in food prices in 2008 [3]. Each day the average American throws away a half-pound $(0.2 \mathrm{~kg})$ of wasted food, which over the course of the year averages 197 pounds $(89.5 \mathrm{~kg})$ per person, a total which has doubled since 1974 [4]. The complexity of this issue does not allow a specific event or date on the calendar to say this is when the culture of food waste excess began. However, it is possible to link the "theatre of super abundance" [5] and excessive increases of food waste to the continual increases in crop yields during the past half century. With the coming of the chemical era of agriculture, using fossil fuel-based fertilizers, pesticides, and herbicides, which in turn doubled and tripled the annual crop yield, so too did the consumers' expectations for visual appealing "perfect" food, only to discard the excess as waste.

It is estimated that nineteen percent of all the waste placed in landfills annually in the United States is food waste. This is not just a loss of food, but other finite resources. We are chomping our way through reserves of oil, soil, forests and aquifers that have taken millions of years to develop, and we are not even making good use of them as we do so [6]. This simply is not a sustainable model of food production or consumption. It is time to factor in waste as a critical part in creating a new food system, one that closer to the consumer with the ability to find new ways of using waste to grow more food. Now is the time to shift fresh food production to metropolitan and periurban regions, not just seasonally, but all year round, using food waste as just one of the components to grow more food. To understand why this shift needs to occur, one must first understand the current food system. 


\section{Understanding our current food systems}

Our current food system is dependent upon the prevailing rural industrial/chemical farming system that rests upon relatively stable climates in addition to the unlimited availability of cheap energy, surplus fresh water, and arable land.

In the twenty-first century, all of these factors are in steep decline. One of the largest obstacles to local/regional food production is the prevailing food system itself. The current food industry and the global shipping (logistics) industries prefer the status quo [7]. Changing this will require a fundamental shift in where and how food is grown in the twenty-first century, and potentially solve the food waste issue at the same time.

Building regional food resilience would provide a viable alternative to the current food system. One can read any number of the recent publications on food and food systems, and find a call for building new ways of growing and delivering food to the consumer in order to address one or more of the above factors. Table 1 breaks down four primary limitations of the existing food production/industrial farming sector of United States economy: energy, water, land, and weather conditions. Think of each of these quadrants also contributing to the increase in food waste.

Table 1: $\quad$ Current state of U.S. industrial agriculture.

\begin{tabular}{|l|l|}
\hline \multicolumn{1}{|c|}{ Energy/Fossil Fuels } & \multicolumn{1}{c|}{ Fresh Water } \\
\hline $\begin{array}{l}\text { The U.S. spends approximately } \$ 700 \\
\text { billion per year on fossil fuels }\end{array}$ & $\begin{array}{l}\text { Fresh water is a non-renewable } \\
\text { resource }\end{array}$ \\
$\begin{array}{l}\text { 19\% of all fossil fuels are used to } \\
\text { grow, process, and transport food to } \\
\text { both the U.S. and global } \\
\text { communities }\end{array}$ & $\begin{array}{l}\text { Land } \\
\text { Agriculture/food production uses } 80 \% \\
\text { of the available fresh water annually }\end{array}$ \\
\hline $\begin{array}{l}\text { Arable farmland is a finite resource } \\
\text { The US loses one acre of farmland }\end{array}$ & $\begin{array}{l}\text { Of } 950 \text { natural disasters in } 2010,90 \% \\
\text { were related to extreme weather } \\
\text { incidents }\end{array}$ \\
$\begin{array}{l}\text { Our fresh food production is } \\
\text { increasingly in the path of urban } \\
\text { development, this encroachment } \\
\text { places fresh food production in peril. }\end{array}$ & $\begin{array}{l}\text { Meteorological calamities are } \\
\text { becoming increasingly common, } \\
\text { further disrupting traditionally grown } \\
\text { food supplies. }\end{array}$ \\
\hline
\end{tabular}

Advanced Energy Growing ${ }^{(}, 2011$. 


\section{Food waste in the current food system}

For many American consumers food comes from the supermarket. With less than two percent of the population currently engaged in the growing and harvesting of food, is it any wonder that food knowledge has declined as the crop yields have increased. Long before the food arrives at the supermarket, the process of food waste has already begun. Yet, for the average consumer convenience trumps homemade, and appearance trumps taste when it comes to the selection of food for daily sustenance. These food choices, made by consumers every time they visit their local supermarket, affect the entire food chain in our current food system.

To understand the process, it may be the simplest to follow one food choice, bagged baby lettuce from the typical California grower to the East Coast supermarket and consumer in the United States. Bagged fresh baby greens have become a standard in nearly every produce department of every grocery store (approximately 35,000 in the United States). These greens are placed in Modified Atmosphere Packaging (MAP) [8], filled with gases that preserve the fresh look as if the salad had just been picked.

Chances are, the farmers growing the baby greens planted twice as much as the contract calls for to ensure that there would be enough product to fill that contract. Now of harvest/picking the freshness countdown clock begins, which for baby greens is approximately 15 days of shelf life once picked. The overage planted to ensure having enough product to fulfil the contract with the buyer is often left in the fields, and at this early stage of the food chain is the first level of waste. The greens that were picked will be transported to a packaging facility to be washed, bagged with the MAP technologies, and refrigerated, on average taking six days to be processed and delivered to a food distribution center on the East Coast via refrigerated trucks or trains making up 20 percent of all U.S goods shipped each year.

Once at the distribution center, the buyer inspects the cases of baby greens to ensure that they meet the USDA guidelines. If they meet the guidelines they are placed in refrigerator units waiting for distribution to supermarkets, if not, the grower (not the buyer) is now stuck with either finding another buyer, or a means to get an 18-wheel semi-truck load of baby greens to a landfill or compost facility.

For those bags of baby greens that finally make it to the supermarkets, which could be another two to three days depending on the inventory at the individual supermarkets, there is another inspection, and refrigeration process to ensure the product continue to meet the USDA guidelines. By this time, in the food to consumer chain, there may be only 2-3 days before the "sell buy" date stamped on the bag expires. Once that expiration date has arrived, whether the product ever made it to the store shelf for sale, it is culled and thrown away. An estimated 32 percent of fresh vegetables in supermarkets, restaurants, and households are wasted [9].

The product that makes its way to the consumer arrives in the household and is placed in another refrigerating unit. When the MAP bag is opened by the 
consumer, and exposed to oxygen, the product can and will deteriorate rapidly, often resulting in partially used bags of product discarded by the consumer. This discarding of food waste is universal in the United States and occurs in households of all socioeconomic levels.

The average meal (from farm to fork) in the current food system is an energyintensive and environmentally intensive process. Bloom [10] argues that from production to cooking, and taking into account the required refrigeration along the food chain that the energy needed to cook the average meal in an American home is a larger investment in energy dollars for food than any other energy use, save heating and cooling the home itself.

All along this journey from field to fork, there has been waste, and estimated fifty percent of what is grown in the United States is wasted [11]. While it is easy to see the connection to soil depletion and energy use, there is another invisible commodity, water that is also being depleted in this over-production and distribution process. Potable water could be said to be a "given" to most Americans, who have few, if any, disruptions in their water supplies. It is expected that when one turns on the tap, fresh, clean water will appear. However, with the overuse of water to produce crops, (of which over thirty percent are using water from aquifers and dispersed by irrigation systems), we are using a non-renewable resource, water, which ends up as food waste in landfills.

Arable land. Energy. Water. While others around the globe are addressing these issues and there vital connection to an ever expanding waste stream, it seems that the United States continues to have a habit of abundance, which results in food, and the energy and water used to produce it, to be casually thrown away. The disconnect between natural resources and finite limitations will require not only a building of a new regionally-based food system, but also a major behavioural shift from individual consumers. Today, the technologies are available to begin the former. Perhaps the latter will catch up as connections to food production begin to move closer to where the consumer lives and eats.

\section{Creating a new food system to reduce/recycle waste}

There is a saying "one man's trash is another's treasure." Perhaps it is time to begin to look at waste with different point of view, one of opportunity to change food production systems in the short-run, and build long-term solutions to the waste conundrum that is now invisible to the average American. Rather than being a broken link in the food chain, waste, must be shown to be an integral, transformational, point that provides energy to grow food in a more sustainable manner.

A United States government report framed sustainable agriculture as the fourth major era in agriculture (following the horsepower, mechanical, and chemical eras), stating that the new era could be more profound than those of the previous agricultural revolutions [12]. Perhaps the answers to creating a new sustainable food system must include the entire spectrum of consumers and political entities from urban (core), suburbia, periurban, and rural communities 
address the issues of arable land, energy, water, and waste, not in the current industrial agriculture sector.

Table 2, Characteristics of a Sustainable Food Systems for Urban/Metro Regions, outlines the natural recourses and weather advantages if we but take into consideration a new twenty-first century food system based upon a recent study by the American Planning Association (APA) [13]. It is at the nexus of energy, water, land, and increasing extreme weather conditions lays a potential new and creative approach to feeding the metropolitan communities of the twenty-first century. This new system can and must co-exist with traditional agricultural practices even though other food production sectors (primarily commodity growers) face an uncertain future given their dependence upon fossil fuels. Reshaping the part of the food system that is flexible and malleable to new growing techniques will reduce the dependency of fresh food upon fossil fuels.

Table 2: Characteristics of a sustainable food system for urban/metro regions.

\begin{tabular}{|c|c|}
\hline Using Renewable Energy Sources & $\begin{array}{c}\text { Reducing Water Consumption } \\
\text { and Increasing Water } \\
\text { Conservation } \\
\end{array}$ \\
\hline $\begin{array}{l}\text { Use biomass/waste-to- } \\
\text { energy to grow food; } \\
\text { provide resulting compost } \\
\text { from the process for local use }\end{array}$ & $\begin{array}{l}\text { Collect and filter storm } \\
\text { water to conserve water } \\
\text { - Use advanced filtering and } \\
\text { recycling }\end{array}$ \\
\hline $\begin{array}{l}\text { Participate in resource } \\
\text { sharing among/between other } \\
\text { regional businesses } \\
\text { committed to reuse of } \\
\text { resources }\end{array}$ & $\begin{array}{l}\text { Apply technologies to } \\
\text { reduce the amount of water } \\
\text { needed to grow fresh food }\end{array}$ \\
\hline $\begin{array}{c}\text { Developing Supportive Land Use } \\
\text { Policies }\end{array}$ & $\begin{array}{l}\text { Mitigating Extreme Weather } \\
\text { Impact }\end{array}$ \\
\hline $\begin{array}{l}\text { Target the use of marginal } \\
\text { lands in urban, suburban, } \\
\text { periurban and rural } \\
\text { communities to grow food, } \\
\text { thus supporting farmland } \\
\text { preservation and } \\
\text { conservancy of natural } \\
\text { habitats }\end{array}$ & $\begin{array}{l}\text { - Create controlled } \\
\text { environments that can } \\
\text { withstand extreme weather } \\
\text { fluctuations, and minimize } \\
\text { the impact of weather on } \\
\text { growing crops }\end{array}$ \\
\hline
\end{tabular}




\section{Food waste to grow food: opportunities and challenges}

Food waste is not something one often considers in the United States as a medium that can contribute to growing food, given that it has to date been buried in landfills. Out of sight, out of mind. With the heavily subsidized corn industry taking center stage as the choice of biofuel, biogas generation from food waste has received comparatively little attention. Given all of the waste in the current food chain, there appears to be a steady stream of readily available biomass to convert to energy to contribute to the growing of food, be it to run the machinery or other growing technologies, deliver locally-grown food, or using the compost residuals to replenish the soil. Considering that little food waste is currently even being diverted to composting facilities, there are ways for sustainable agriculture to play a role in transforming the current food system. It is time for sustainable agriculture to stake a claim on the opportunities that can come from finding solutions through the linking of "food waste" as an integral part of food growing.

The first step is in resetting the perception that agriculture, particularly sustainable agriculture is not high tech. "It is curious that the modern categorization of the Organization for Economic Cooperation and Development (OECD) and the EU benchmarked against some often arbitrarily designated category like "high tech" or "knowledge-economy", agriculture and the food industry are perceived to be uncritically as "low-tech" when in truth it is scarcely possible to find, in its intensive manifestation to be sure, a more science and technology saturated sector on earth" [14]. The oversight that a mature industry such as agriculture is not capable of recreating itself through technological applications takes away the most basic of needs, research and development (R \& D) monies to push the industry forward. While highly subsidized areas of agriculture receive plentiful $\mathrm{R} \& \mathrm{D}$ through private sector funding, those involved on what is often perceived as the margins of agriculture, the nonsubsidized crops, particularly vegetable and fruit growers and those engaged in sustainable approaches, face formidable challenges to accessing pre-seed, R \& $\mathrm{D}$, and ultimately venture capital investment.

With that challenge being addressed, it is possible to link strategic industries, private sector companies, and public sector institutions together to find solutions to the waste problem. Until the silos that exist between food producers and haulers of waste are removed, there will be continuing turf wars. Understanding, that in the United States many of the landfills are owned and operated by those who pick up the waste, the status quo may be what these businesses will support. Some in the waste industry are beginning to look at capturing the flared methane from the landfill, but are doing so in ways that still do not capture the majority of the gases being dispersed into the atmosphere. Others are considering co-locating anaerobic digesters next to or near landfills to divert food waste and create energy to sell back to the existing power grid.

The EU is far advanced in using anaerobic digesters to divert food waste from landfills, create energy, and return the compost to the local farmers to use on their fields. While biogas is expensive to upgrade to motor fuel quality, "it could be of better use within the agriculture sector itself, thus reducing dependency on 
fossil fuels and improving food security" [15]. There are many dairy farmers in the United States, including Amish farmers, who are installing such digesters to use the manure from their dairy herds, to generate power to run the cooling tanks and other needs in the processing of the milk produced by their cows. In several instances, these farmers have been able to diversify their farms by co-locating small-scale greenhouses to grow vegetables, using the power generated by the digesters.

Another viable path to capture the energy of food waste is the use of anaerobic digesters, co-located by municipal solid waste plants. Food waste is the third largest component of municipal solid waste generated in the United States [16]. Worldwide, biogas is mainly used in combined heat and power (CHP) applications, whereas various EU countries are experimenting with conversion to motor fuel. The EU has some of the oldest digesters in operation. In France, the oldest digesters have been in operation since the end of the 1940s, while seventeen percent of the active digesters came into operation before 1970 [17]. With this long history of digester use, the United States needs to look to the EU, particularly German and Denmark, for the needed solutions to wastewater treatment in municipalities across the nation to reduce food waste streams and produce a high grade of compost to be used in raising the future crops.

\section{The power of regional solutions to waste}

In an era of transparency, it is time for accountability on food waste. Growers, processors, distributors, retail sales (i.e. supermarkets), and consumers all need to be accountable for the level of waste, while so many go hungry (Bloom [18]). gives the order of magnitude in the supermarket sector when he calculated that each supermarket, on average, creates 800 pounds of food waste each day (with 35,000 supermarkets in the United States), which aggregates to 30 million pounds each day, equal to the weight of 9,862 Toyota Prius Hybrid automobiles. Had food waste been statistically documented over the past fifty years, it would have been interesting to track the evolution of "grow-your-own" of the 1930s thru the 1950s and perhaps 1960s to the culture of excess in the 1970s through 2000 s, up to the economic meltdown of 2008. With the growth of farmers' markets, community supported agriculture (CSAs), and growth in backyard gardens, including a revival of home canning and other food preservation techniques.

With transparency locally/regionally, what if the local supermarkets were scored on the level of food recycled, composted, or digested? Would this make a difference to the shoppers? Until real numbers are associated with waste where individuals shop, eat out, and cook at home, it will, given the current American culture, remain someone else's problem. Bloom calls for landfill taxes, and recycling bins just for food waste. While there will be pushback from the consumers, in the long run, it will be part of everyday life in the not too distant future.

Perhaps the near future even bodes well for the decline in long distance hauling of food waste, often across state lines. One quarter of the trash that 
Americans bury or burn, every year has crossed state lines. Between 1995 and 2005, interstate shipments of trash have more than doubled, with Pennsylvania, Michigan, and Virginia becoming key dumping grounds [19]. Would citizen in the local region approve of such dumping if they knew that the hazards of the materials disposed of in their local landfills would have local repercussions for $30+$ years, probably not.

The first step in reducing food waste is to get people thinking about it, in a way that is meaningful for them. Perhaps the first sentence of Bloom's recent treatise on this subject in America would be the fodder for a series of public service announcements, "Everyday, America wastes enough food to fill the Rose Bowl, a 90,000 seat football stadium" [20]. It could be said the time is right to take the next step in looking at our food system waste stream.

\section{References}

[1] London Evening Standard, 2-21-2011.

[2] Bloom, J. American Wasteland. Da Capo Press: Philadelphia, Pennsylvania, p.275, 2010.

[3] Glennon, R. Unquenchable: America's Water Crisis and What to Do About It. Island Press: Washington, p.276, 2009.

[4] Bloom, J. American Wasteland. Da Capo Press: Philadelphia, Pennsylvania, p.xii, 2010.

[5] Steel, C. Hungry City: How Food Shapes Our Lives. Vintage Press: London, p.268, 2008.

[6] Steel, C. Hungry City: How Food Shapes Our Lives. Vintage Press: London, p.269, 2008.

[7] Tumber, C., Small, Gritty, and Green: The Promise of America's Smaller Industrial Cities in a Low-Carbon World, Massachusetts Institute of Technology: Cambridge, MA, 2012.

[8] Bloom, J. American Wasteland. Da Capo Press: Philadelphia, Pennsylvania, p.148, 2010.

[9] Kantor, L.S., Lipton, K., Manchester, A., and Oliveria, V. Estimating and Addressing America's Food Losses. Food Review, 3, 1997.

[10] Bloom, J. American Wasteland. Da Capo Press: Philadelphia, Pennsylvania, p.19-20, 2010.

[11] Steel, C. Hungry City: How Food Shapes Our Lives. Vintage Press: London, p.269, 2008.

[12] U.S. General Accounting Office. Sustainable Agriculture: Program Management, Accomplishments, and Opportunities. Washington, DC: U.S. Government Printing Office, GAO/RCED-92-233, 1992.

[13] Peemoeller, L. Sustainable Food Systems, (Chapter 9). Sustainable and resilient communities, ed. Coyle, S.J. \& Duany, A., John Wiley and Sons: Hoboken, NJ, 2011.

[14] Cooke, P. Cleantech and an Analysis of the Platform Nature of Life Sciences: Further Reflection upon Platform Policies. European Planning Studies 16, 3, p. 375-382, 2008. 
[15] Johansson, K, Liljequist, K., Ohlander, L., and Aleklett, K. Agriculture as Provider of Both Food and Fuel. AMBIO, 39, pp. 91-99, 2010.

[16] Chen, X., Romano, R.T., and Zhang, R. Anaerobic digestion of food waste for biogas production. International Journal of Agricultural and Biological Engineering, 3, pp. 61-71, 2010.

[17] Bodik, S, Sedlacek, M. and Hutnan, M. Biogas Production in Municipal Waste Water Treatment Plants: Current Status in EU with a Focus on the Slovak Republic. Chemical and Biochemical Engineering Quarterly, 25, 3, pp. 335-340, 2011.

[18] Bloom, J. American Wasteland. Da Capo Press: Philadelphia, Pennsylvania, p.150, 2010.

[19] Bloom, J. American Wasteland. Da Capo Press: Philadelphia, Pennsylvania, p.23, 2010.

[20] Bloom, J. American Wasteland. Da Capo Press: Philadelphia, Pennsylvania, p.xi, 2010. 